\title{
sciendo
}

\section{PERCEIVED STRESS, BURNOUT AND ANXIETY AND FEAR RELATED TO COVID-19 IN ROMANIAN MEDICAL STUDENTS - EXPERIENCE FROM THE STATE OF EMERGENCY IN ROMANIA}

\author{
KRISZTINA-AGOTA ARMEAN ${ }^{1}$, CODRUȚA-ALINA POPESCU ${ }^{2}$, SEBASTIAN-MIHAI \\ ARMEAN $^{3}$, BOGDAN-FLORIN COVALIU ${ }^{4}$, PETRU ARMEAN ${ }^{5}$, ANCA-DANA BUZOIANU $^{6}$ \\ 1,2,3,4,6 “Iuliu Hațieganu” University of Medicine and Pharmacy, Cluj-Napoca, " 'Carol Davila” University of Medicine and Pharmacy, Bucharest
}

\begin{abstract}
Keywords: COVID-19, perceived stress, burnout, fear, anxiety, mental
\end{abstract} health, medical students

\begin{abstract}
Crisis situations, which cause disturbances in the daily routine of the individual can contribute to the development of mental problems. On the $26^{\text {th }}$ of February, 2020, the first confirmed case of COVID-19 was reported in Romania. On the $16^{\text {th }}$ of March, the President of Romania declared The State of Emergency. The following day, by Order of the Ministry of the Internal Affairs medical students starting with the $4^{\text {th }}$ year of study were to be recruited, on a voluntary basis, to support activities in the Emergency Rooms, if needed. Numerous medical students volunteered. The medical students were exposed to online learning and the possibility of being recruited as volunteers in COVID-19 units. In April 2020, we created and distributed an online survey via www.psysafe.org, which collected data on demographics, personal status of infection, and general mental health, including medication and substance use, sleeping problems in the previous week, perceived stress in the previous month, and burnout in the previous two months. We translated and adapted 2 questionnaires to assess the COVID-19 related anxiety and fear. The participants were Romanian medical students. Data was statistically analysed with SPSS 20. Out of 550 surveys filled, we analysed 545 valid surveys. The mean age of the respondents was $21.66( \pm 2.55)$ years, with $81.7 \%$ female $(445)$ and $18.3 \%$ male (100). $91.6 \%$ of the respondents declared that they were never diagnosed with a psychiatric disorder. Coffee was used on a daily basis by $53.8 \%$ of the students, with tobacco coming in second in 19.4\%. Female students perceived a higher level of stress and showed a higher level of burnout. Female students scored higher for the anxiety and fear related to Covid-19. Medical students with mental health history scored higher on perceived stress, burnout, anxiety and fear related to COVID-19. Perceived stress indicated a level of moderate stress regardless of the mental history status. For all students, the burnout value indicated that some attention was needed, as they might had been candidates to burnout. Moreover, students diagnosed with a psychiatric disorder during the pandemic showed signs that they were on the road to burnout, with changes needed to be done at the time. There were statistically significant positive correlation, of various degrees between perceived stress, burnout, anxiety and fear related to COVID-19, with the strongest one observed for the perceived stress and burnout, in Romanian medical students.
\end{abstract}

\begin{abstract}
INTRODUCTION
Crisis situations, which cause disturbances in the daily routine of the individual can contribute to the development of mental problems such as depressive, anxious disorders, increased irritability. These disturbances are reported in particular in the conditions of divorce, loss of employment or other major changes in life.(1) Crisis situations requiring the quarantine of entire regions or countries inevitably lead to dramatic disruptions and changes in the labour market, with reduced activity or job loss. People who go through these changes in radical changes in daily routine report higher scores on scales that assess depressive symptomatology.(2) According to network theory, symptoms of a psychiatric disorder can lead to the development of another psychiatric disorder. Therefore, the co-existence of two psychiatric disorders belongs to a dynamic network of symptoms that produce and maintain the psychopathological picture. Common symptoms connect the two
\end{abstract}

pathologies, and the activation of the common symptom increases the risk of "transferring" symptoms from one disorder to the other.(3) Co-activation of two psychiatric disorders can be observed in crisis situations, for example epidemics, when either anxiety or depression is triggered, and failure to resolve one of them, most commonly anxiety, leads to the development of the other by transferring symptoms.(4)

As we have seen, irritability is a structure that retains stability over time, and exposure to stressful situations, causes anger responses; if the situation is not resolved, but is chronic, chronic irritability increases the risk of developing depressive disorder. Such a pressing situation, which drags on and whose resolution is not in the cross-reference, is a major epidemic crisis, in which limited resources are engaged in survival. Added to this, the instability created by the loss of daily routine, which can in turn lead to the development of symptoms of irritability and depression. Moreover, irritability and sadness, specific to

${ }^{1}$ Corresponding author: Sebastian-Mihai Armean, Str. Ghe. Marinescu, Nr. 23, Cluj-Napoca, România, E-mail: sebastian.armean@umfcluj.ro, Phone: $+40374834825$

Article received on 10.05.2021 and accepted for publication on 04.06.2021 


\section{PUBLIC HEALTH AND MANAGEMENT}

depression, are part of the same class of affect disturbances, with negative valences.

On the $26^{\text {th }}$ of February, 2020, the first confirmed case of COVID-19 was reported in Romania. On the $16^{\text {th }}$ of March, the President of Romania declared The State of Emergency (5) which was in effect until May, the $14^{\text {th }}$. On the $17^{\text {th }}$ of March 2020, by Order no. 74522 issued by the Ministry of the Internal Affairs At the level of each university centre, within the medical faculties, students will be recruited, starting with fourth year medical students, on a voluntary basis, to support activities in the Emergency Rooms. Recruited students only carry out support activities if the current capacity of medical facilities is exceeded.(6) Numerous medical students volunteered to be recruited.(7) So, the medical students were exposed to online learning and the possibility of being recruited as volunteers in COVID-19 units. Irritability is understood as an inclination, as a predisposition to react with anger, to stir up gallows or to have tantrums, manifestly disproportionate to the situation or the stimulus that causes the response.(8) Irritability is part of affect disturbances, with both positive and negative valences. On the one hand, from the point of view of origin, it is classified as a disturbance in a negative sense, alongside fear and sadness, and on the other hand, from the point of view of the result it is classified as a disturbance in a positive sense, alongside exaltation. Fear and sadness cause withdrawal behaviour, while exaltation, but also irritability, causes opposite behaviour of closeness.(9) Irritability, either as a symptom (10), or as a trait, does not currently benefit from a specific drug treatment. The underlying or comorbid pathology is frequently addressed, which brings with it and therapeutic response to the problem of irritability. This case is commonly found in psychiatry, where a pharmacotherapeutic class treats several pathologies.

Population studies have shown that irritability forms a distinct framework (8), with substantial stability over time, associated with depression and anxiety in longitudinal studies.(11) Moreover, it seems that the superposition with depression also has a genetic part. It has been demonstrated by longitudinal studies that irritability is associated with depressive symptoms but that this association is less if studied in relation to anxiety or symptoms of ADHD.(12) Persistent irritability has also been shown to be associated with depressive symptoms.(13)

\section{MATERIALS AND METHODS}

Population

The participants were young adults, over 18 years, Romanian medical students, from any medical school in Romania. Each participant gave an informed consent electronically.

\section{Survey}

In April 2020, we created and distributed an online survey via www.psysafe.org, which collected data on demographics, personal status of infection, personal status of public health measures disposed, a close person's status of infection, and general mental health. We assessed the participants' sleeping problems in the previous week, perceived stress (14) in the previous month, and burnout (15) in the previous two months, as presented in Annex 1. Sleepless nights or nights with sleeping problems as well as using sleeping pills counted as a sleeping problem. We used the Perceived Stress Scale (PPS) because its evidence for validity prove higher PSS scores were associated with "greater vulnerability to stressful life event, elicited depressive symptoms, or more colds". The outbreak of COVID-19 was a stressful life event, and in the beginnings, there were some voices who considered it not more dangerous than a common cold. We adapted the Burnout Rating Scale (BRS), from the original 3 months period it to a 2-month period so we would have a more accurate depiction of the phenomenon during the State of Emergency.

The items for the general mental health were classified as: a) personal history of mental illnesses, b) use of psychiatric medication and self-medication, including use of supplementary products c) substance abuse.

We translated and adapted 2 questionnaires to assess the COVID-19 related anxiety and fear. The first questionnaire was developed by Ho et al (2005) (16), and the second one by Ahorsu et al (2020).(17) The first questionnaire has 18 items, so we named it COVID-19 Fear-18 (CF-18). We assessed the participants' opinion via a 4-point Likert scale, 0 - definitely false, 3 - definitely true. The second questionnaire, Fear of Coronavirus-19 Scale has 7 items, so we named it COVID-19 Fear-7 (CF-7). We assessed the participants' opinion via 5-point Likert scale 1 - strongly disagree, 5 - strongly agree as presented in Annex 1.

To simplify the survey, we used the term COVID-19 for both the disease and the virus. Surveys not entirely filled were considered invalid. Data was collected from late-April to the end of May 2020.

Statistical analysis

Data was statistically analysed with SPSS 20. The research received the Approval of the Ethics Committee of the Iuliu Hațieganu University of Medicine and Pharmacy ClujNapoca, Romania.

The entire questionnaire is available upon request.

\section{RESULTS}

Out of 550 surveys filled, 5 had missing responses, so they were excluded from the statistical analysis. In the end, we analysed 545 valid surveys. The mean age of the respondents was $21.66( \pm 2.55)$ years, with $81.7 \%$ female (445) and $18.3 \%$ male (100). $95 \%$ of the respondents (518) were single, $2.8 \%$ married (15), and the rest in other forms of partnership.

At the time, $85.3 \%$ (465) of the respondents declared that they were not or have not been infected with SARS-CoV-2, and $14.7 \%$ (80) declaring that did not know. On the other hand, $71 \%$ (387) declared that they did not know a close person to be ill, $18.7 \%$ (105) that the person was cured, $8.4 \%$ (46) that the person was still ill, and $1.8 \%$ (10) that the person had died.

The percentage of respondents who were or have been placed in self-isolation was $38.2 \%$ (208), in quarantine $4.6 \%$ (25), with $57.2 \%$ (312) not placed in quarantine or self-isolation.

The personal history of mental illnesses is presented in table no. 1 . There were $4.8 \%$ of the respondents who declared that they had been diagnosed with a psychiatric disorder in the past, and $3.3 \%$ of the respondents who declared that they were diagnosed at the time of the study. $91.6 \%$ of the respondents declared that they were never diagnosed with a psychiatric disorder.

Table no. 1. Relative frequency of personal history of mental illnesses, results in percentage $(\%)$

\begin{tabular}{|l|l|}
\hline Personal history of mental illnesses & \\
\hline None & 91.6 \\
\hline In the past & 4.8 \\
\hline In the present & 3.3 \\
\hline
\end{tabular}

Table no. 2 presents the relative frequency of the use of psychiatric medication and self-medication, including the use of supplementary products in the Romanian medical students. $3.1 \%$ declared that they had received previous psychiatric medication, and $5.5 \%$ declared that they used self-medication, including supplements, in the past, while $1.7 \%$ declared that they were on a current medication, and $5.7 \%$ that they selfmedicate currently. 


\section{PUBLIC HEALTH AND MANAGEMENT}

Table no. 3 presents the relative frequency of psychoactive substance use in Romanian medical students. Coffee was used on a daily basis by $53.8 \%$ of the students, with tobacco coming in second in $19.4 \%$, and tea in third place with $8.8 \%$. Daily alcohol consumption was reported by $1.7 \%$ of the Romanian medical students. $66.7 \%$ of the Romanian medical students declared that they had never smoked, $34.3 \%$ that they had never drunk alcohol, and $23.1 \%$ that they had never drunk coffee.

Table no. 2. Reported use of medication, including supplements, results in percentage $(\%)$

\begin{tabular}{|l|l|l|}
\hline Have you used & No & Yes \\
\hline Previous psychiatric medication & 96.9 & 3.1 \\
\hline Previous self-medication (including supplements) & 94.5 & 5.5 \\
\hline Current psychiatric medication & 98.3 & 1.7 \\
\hline Current self-medication (including supplements) & 94.3 & 5.7 \\
\hline
\end{tabular}

Table no. 3. Reported use of psychoactive substances, results in percentage $(\%)$

\begin{tabular}{|c|c|c|c|c|c|c|c|c|c|}
\hline $\begin{array}{c}\text { How } \\
\text { often } \\
\text { do you } \\
\text { use }\end{array}$ & $\begin{array}{l}\bar{\Xi} \\
\overline{\frac{\Xi}{\pi}}\end{array}$ & 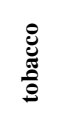 & 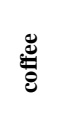 & $\Xi$ & 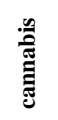 & 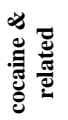 & む) & क् & : \\
\hline Never & 34.3 & 66.7 & 23.1 & 45.6 & 95.4 & 98.6 & 99.4 & 99.1 & 95.3 \\
\hline $\begin{array}{l}\text { Once a } \\
\text { month }\end{array}$ & 24.2 & 4.1 & 3.1 & 17.3 & 2.4 & 1.2 & 0.6 & 0.7 & 1.6 \\
\hline $\begin{array}{l}\text { Twice a } \\
\text { month }\end{array}$ & 12.7 & 1.4 & 3.7 & 8.1 & 0.7 & 0.2 & 0.6 & 0.2 & 0.5 \\
\hline $\begin{array}{c}\text { Once a } \\
\text { week }\end{array}$ & 13.3 & 2.3 & 5.0 & 7.9 & 0.2 & 0 & 0 & 0 & 1.3 \\
\hline $\begin{array}{c}2-3 \\
\text { times a } \\
\text { week }\end{array}$ & 13.8 & 6.2 & 11.4 & 12.4 & 1.0 & 0 & 0 & 0 & 1.3 \\
\hline Daily & 1.7 & 19.4 & 53.8 & 8.8 & 0.2 & 0 & 0 & 0 & 0 \\
\hline
\end{tabular}
presented in figure no. $1.37 .6 \%$ of the medical students declared that they had trouble sleeping for at least 1 night during the past week.

Figure no. 1. Sleeping problems (nights/week), result in percentage $(\%)$

\section{Sleeping problems (nights/week) (\%)}

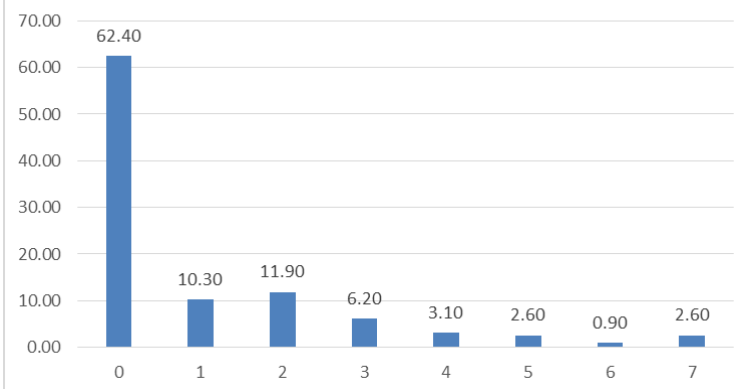

Table no. 4 presents the distribution of the mean scores for each of the 4 domains and their relationship with the participant's gender. According to the PPS mean score, female students seem to perceive a higher level of stress. Both values indicate that the medical students perceived a moderate level of stress. According to the BRS mean score, female students seem to show a higher level of burnout, with the value correspondent to some attention needed, for they may be candidates to burnout. On the other side, male students did not show any signs of burnout. The same differences have been observed when assessing the anxiety and fear related to Covid-19, with higher values for female students compared to male students.
Table no. 4. Gender distribution of mean scores for perceived stress, burnout, and anxiety and fear related to Covid-19

\begin{tabular}{|c|c|c|c|c|}
\hline & Gender & Mean & $\mathrm{t}$ & $\mathrm{p}$ \\
\hline PPS_score & Male & 16.0900 & -4.509 & .000 \\
\hline & Female & 19.5663 & -4.535 & .000 \\
\hline BRS_score & Male & 14.6500 & -4.650 & .000 \\
\hline & Female & 20.4831 & -4.808 & .000 \\
\hline CF-18_score & Male & 13.6000 & -4.376 & .000 \\
\hline & Female & 17.6921 & -4.245 & .000 \\
\hline CF-7_score & Male & 11.0800 & -5.497 & .000 \\
\hline & Female & 14.1393 & -5.865 & .000 \\
\hline
\end{tabular}

As shown in table no. 5, Romanian medical students who were diagnosed with a psychiatric disorder at the time of the outbreak of the Covid-19 pandemic present higher values for the mean scores on all 4 domains. Medical students who had been diagnosed with a psychiatric disorder prior to the outbreak scored higher than medical students with a free personal history of mental illness on all 4 domains. Perceived stress mean value indicate a level of moderate stress regardless of the mental history status. According to the BRS mean score, students with medical free history and students that had been diagnosed with a psychiatric disorder in the past, the value corresponds to some attention is needed, as they may be candidates to burnout. Moreover, students diagnosed with a psychiatric disorder during the pandemic showed signs that they were on the road to burnout, with changes needed to be done at the time.

Table no. 5. Personal history of mental illnesses and the distribution of mean scores for perceived stress, burnout, and anxiety and fear related to Covid-19

\begin{tabular}{|l|l|l|l|l|}
\hline $\begin{array}{l}\text { Mental illness } \\
\text { history }\end{array}$ & PPS_score & BRS_score & $\begin{array}{l}\text { CF- } \\
\text { 18_score }\end{array}$ & $\begin{array}{l}\text { CF- } \\
\text { 7_score }\end{array}$ \\
\hline None & 18.5591 & 18.8778 & 16.7174 & 13.4790 \\
\hline In the past & 22.5769 & 24.3077 & 18.8077 & 14.8462 \\
\hline In the present & 24.4444 & 28.4444 & 21.5000 & 15.0000 \\
\hline Total & 18.9466 & 19.4549 & 16.9761 & 13.5948 \\
\hline
\end{tabular}

The distribution of mean scores for the 4 domains and the relationship with the use of psychiatric medication is presented in Table 6. The mean scores for PPS and BRS were higher for the students who used psychiatric medication, although showing the same level of moderate stress perceived and some attention needed when looking at the burnout signs, because they may be candidates. The CF-18 and CF-7 mean scores were lower for the students who used medication.

Table no. 6. Psychiatric medication use and the distribution of mean scores for perceived stress, burnout, and anxiety and fear related to Covid-19

\begin{tabular}{|l|l|l|l|l|}
\hline $\begin{array}{l}\text { Psychiatric } \\
\text { medication }\end{array}$ & PPS_score & BRS_score & $\begin{array}{l}\text { CF- } \\
\text { 18_score }\end{array}$ & $\begin{array}{l}\text { CF- } \\
\text { 7_score }\end{array}$ \\
\hline No & 18.8954 & 19.2909 & 17.0133 & 13.5951 \\
\hline Yes & 20.5294 & 24.5294 & 15.8235 & 13.5882 \\
\hline Total & 18.9466 & 19.4549 & 16.9761 & 13.5948 \\
\hline
\end{tabular}

The distribution of mean scores for the 4 domains and the relationship with the use of alcohol is presented in table no. 7. The medical students who declared that they consume alcohol daily reported the highest mean scores for both PPS and BRS. Overall, the amount of perceived stress is levelled as moderate, and the BRS score indicate that some attention is needed. Moving to anxiety and fear related to Covid-19, the medical students who consumed alcohol 2-3 times a week scored highest at both $\mathrm{CF}-18$ and CF-7.

As shown in Table 8, medical students who use alcohol have a statistically significant higher mean for perceived stress, burnout, and CF-18, but not for CF-7. 


\section{PUBLIC HEALTH AND MANAGEMENT}

Table no. 7. Alcohol use and the distribution of mean scores for perceived stress, burnout, and anxiety and fear related to Covid-19

\begin{tabular}{|l|l|l|l|l|}
\hline Alcohol use & PPS_score & BRS_score & CF-18_score & $\begin{array}{l}\text { CF- } \\
\text { 7_score }\end{array}$ \\
\hline Never & 17.7078 & 17.2237 & 15.8402 & 13.1598 \\
\hline Once a month & 19.4478 & 19.9701 & 17.0149 & 13.7836 \\
\hline Twice a month & 18.7500 & 19.0500 & 17.3833 & 13.8667 \\
\hline Once a week & 19.8197 & 20.5574 & 16.6393 & 13.5902 \\
\hline $\begin{array}{l}\text { 2-3 times a } \\
\text { week }\end{array}$ & 21.0159 & 24.3968 & 20.3492 & 14.3651 \\
\hline Daily & 21.7500 & 24.7500 & 18.0000 & 13.1250 \\
\hline Total & 18.9284 & 19.4128 & 16.9413 & 13.5780 \\
\hline
\end{tabular}

Table no. 8. Distribution of mean scores for perceived stress, burnout, and anxiety and fear related to Covid-19 in alcohol user vs non-user medical students

\begin{tabular}{|l|l|l|l|l|}
\hline & Alcohol use & Mean & t & p \\
\hline \multirow{2}{*}{ PPS_score } & no & 17.7078 & -3.325 & .001 \\
\cline { 2 - 5 } & yes & 19.7485 & -3.277 & .001 \\
\hline \multirow{2}{*}{ BRS_score } & no & 17.2237 & -3.669 & .000 \\
\cline { 2 - 5 } & yes & 20.8834 & -3.654 & .000 \\
\hline \multirow{2}{*}{ CF-18_score } & no & 15.8402 & -2.464 & .014 \\
\cline { 2 - 5 } & yes & 17.681 & -2.477 & .014 \\
\hline \multirow{2}{*}{ CF-7_score } & no & 13.1598 & -1.552 & .121 \\
\cline { 2 - 5 } & yes & 13.8589 & -1.547 & .122 \\
\hline
\end{tabular}

The distribution of mean scores for perceived stress, burnout, and anxiety and fear related to Covid-19 and the personal status of infection are presented in table no. 9. The highest mean scores in all 4 domains were present in the medical students' group that did not know whether they were or had been infected with Covid-19. However, the means were not statistically significant for the CF-7.

Table no. 9. Distribution of mean scores for perceived stress, burnout, and anxiety and fear related to Covid-19 and the personal status of infection

\begin{tabular}{|l|l|l|l|l|} 
& $\begin{array}{l}\text { Are you or have you } \\
\text { been infected with } \\
\text { COVID-19? }\end{array}$ & Mean & $\mathbf{t}$ & $\mathbf{p}$ \\
\hline \multirow{2}{*}{ PPS_score } & No & 18.6602 & -2.136 & .033 \\
\cline { 2 - 5 } & I do not know & 20.4875 & -2.145 & .034 \\
\hline \multirow{2}{*}{ BRS_score } & No & 18.7914 & -3.052 & .002 \\
\cline { 2 - 5 } & I do not know & 23.0250 & -2.946 & .004 \\
\hline \multirow{2}{*}{ CF-78_score } & No & 16.4022 & -3.571 & .000 \\
\cline { 2 - 5 } & I do not know & 20.0750 & -3.695 & .000 \\
\cline { 2 - 5 } & No & 13.4817 & -1.050 & .294 \\
\hline
\end{tabular}

As presented in table no. 10, there are statistically significant positive correlation, of various degrees between all the 4 domains assessed. The strongest correlation has been observed for the PPS and BRS, followed by CF-18 and CF-7.

Table no. 10. Correlations between scores for perceived stress, burnout, and anxiety and fear related to Covid-19

\begin{tabular}{|c|c|c|c|c|c|}
\hline & & $\begin{array}{l}\text { PPS } \\
\text { score }\end{array}$ & $\begin{array}{l}\text { BRS } \\
\text { score }\end{array}$ & $\begin{array}{l}\text { CF- } \\
18 \text { score }\end{array}$ & $\begin{array}{l}\text { CF- } \\
\text { 7_score }\end{array}$ \\
\hline \multirow{2}{*}{ PPS_score } & $\begin{array}{l}\text { Pearson } \\
\text { Correlation }\end{array}$ & 1 & $.755 * *$ & $.569 * *$ & $.384 * *$ \\
\hline & $\mathrm{p}$ & & .000 & .000 & .000 \\
\hline \multirow{2}{*}{ BRS_score } & $\begin{array}{l}\text { Pearson } \\
\text { Correlation }\end{array}$ & $.755 * *$ & 1 & $.590 * *$ & $.437 * *$ \\
\hline & $\mathrm{p}$ & .000 & & .000 & .000 \\
\hline \multirow[t]{2}{*}{ CF-18_score } & $\begin{array}{l}\text { Pearson } \\
\text { Correlation }\end{array}$ & $.569 * *$ & $.590 * *$ & 1 & $.700^{* *}$ \\
\hline & $\mathrm{p}$ & .000 & .000 & & .000 \\
\hline \multirow{2}{*}{ CF-7_score } & $\begin{array}{l}\text { Pearson } \\
\text { Correlation }\end{array}$ & $.384 * *$ & $.437 * *$ & $.700 * *$ & 1 \\
\hline & $\mathrm{p}$ & .000 & .000 & .000 & \\
\hline
\end{tabular}

\section{DISCUSSIONS}

COVID-19 brought numerous changes for every individual. This pandemic is not like any other. Directly affecting the student's routine, in Romania, in some universities, including medical schools, the decision to suspend onsite activities in order to prevent and control the spread of COVID19 has be taken long before the national decisioned brought to law by the declaration of The State of Emergency. The following step was the shift to online teaching activities. Each step, from confirming the first case in Romania to suspending traditional teaching activities and beginning online teaching, represented a major change in the psychological network of the medical students.

The importance of changes in the structure of the psychological network in the context of epidemiological crisis, indicates the central location of irritability. Depressive disorder can also be found in more than $30 \%$ of cases in this situation.(18) Similarly, the prevalence for depressive mood in the acute and post-epidemic epidemic situation, respectively, is $32.6 \%$ and $10.5 \%$, respectively. For irritability, the prevalence is $4.9 \%$ in acute, and $12.8 \%$ post-epidemic. It is worth mentioning the prevalence for aggression, $7.4 \%$ in acute, with a decrease to $1 \%$ post-epidemic.(19) For the general population, it has been noted that more than half of the respondents declared to struggle with anxiety and psychological distress related to COVID-19. Moreover, about $17 \%$ of the respondents considered their level of anxiety as exaggerated, and about a quarter of the respondents considered that their level of anxiety would result in impairment in their daily life.(20)

Out of 550 surveys filled, we analysed 545 valid surveys. The mean age of the respondents was $21.66( \pm 2.55)$ years, with $81.7 \%$ female (445) and $18.3 \%$ male (100). $91.6 \%$ of the respondents declared that they were never diagnosed with a psychiatric disorder. Coffee was used on a daily basis by $53.8 \%$ of the students, with tobacco coming in second in $19.4 \%$.

In previous recent studies conducted in Romania, it was noted that ranging from $15.2 \%$ of medical and law students and $24.7 \%$ of $1^{\text {st }}$ year medical students to $45.3 \%$ of medical students were abstainers from alcohol.(21,22,23,24,25,26) Our results indicate a $34.3 \%$ of medical students, which is in the same range as the other studies. Even though these results seem encouraging, in fact medical students have relatively low levels of knowledge regarding the effect of alcohol on the body.(24) These aspects, corroborated with the daily alcohol use of $1.7 \%$ as shown in table no. 3, during a time of crisis might raise serious concerns, as it is advisable not to resort to psychoactive substance abuse in order to relieve anxiety in stressful conditions, because substance abuse, among others, tends to be associated with an increase in the psychological burden.(20)

The large majority of medical students declared that they had never used cannabis, with $95,4 \%$ of the respondents. This is somewhat similar to the results from the $1^{\text {st }}$ year medical students who declared they had never used in $87,6 \%$ of the respondents.(21) However, in our study, daily smoking was present in $19,4 \%$ cases as opposed to the above-mentioned study with $13,9 \%$. We may attribute the increase in smoking as a mean to cope with anxiety.

Female students perceived a higher level of stress and showed a higher level of burnout. Female students scored higher for the anxiety and fear related to Covid-19. Medical students with mental health history scored higher on perceived stress, burnout, anxiety and fear related to COVID-19. Perceived stress indicated a level of moderate stress regardless of the mental history status. For all students, the burnout value indicated that some attention was needed, as they might had been candidates to burnout. Moreover, students diagnosed with a psychiatric disorder during the pandemic showed signs that they were on 


\section{PUBLIC HEALTH AND MANAGEMENT}

the road to burnout, with changes needed to be done at the time. As almost one quarter of a cohort of Romanian medical students experienced clinically significant depressive symptoms during the exam period, considered to be the most stressful period of the academic year, with nearly $5 \%$ taking antidepressant medication $(23,25,26)$ our study shows that $3.1 \%$ of the medical students had previously taken psychiatric medication and $1.7 \%$ taking it on a current basis, during the time of the pandemic, as presented in table no. 2 , and also that the personal medical history of mental illness as well as the use of psychiatric medication is associated with higher scores for perceived stress, burnout, and anxiety and fear related to COVID-19, as indicated in tables no. 5 and 6 , these issues should also be properly addressed.

Our findings add to those that indicate that patients with personal history of mental illnesses suffer a worsening of their psychiatric symptoms. The same study indicated that patients suffering from COVID-19 may develop post-traumatic stress symptoms in a large proportion, up to $96.2 \%$. Taking into consideration that up to $1 / 4$ of Romanian medical students experience clinically significant depressive symptoms during stressful events, that there was a shift from onsite to online teaching, and that starting from the $4^{\text {th }}$ year, medical students were to be recruited if needed, and therefore exposed to COVID-19 in a potentially similar manner to heath care workers, the findings that people suffering of COVID-19 experience significantly higher level of depressive symptoms, as well as the increased rates of depression and/or depressive symptoms, increased levels of anxiety or any other form of psychological distress as compared to the general populations, represent another potential problem. Poor quality of sleep, reported as insomnia up to $38.9 \%$ was also present in our study group, with $37.6 \%$ of the medical students suffering of sleeping problems at least 1 night a week. $(27,28)$

As the observed anxiety pooled prevalence can raise up to $23.2 \%$ and depression up to $22.8 \%$ during COVID-19 pandemic (28), and that a in a cohort of medical students in Romania, it has been shown that up to $44,1 \%$ of the $1^{\text {st }}$ year medical students suffered from anxiety (21), but with the study conducted long before the outbreak of COVID-19 or any other national crisis, it is very important to address the problem of anxiety in the pandemic context.

The profile for a person developing a mental health problem as depicted in the literature consist of a younger person, healthcare worker (29), female gender and having relatives suffering from COVID-19, with a poor self-related health, people with a personal history of mental illness. $(20,27,28,30)$

On the other side, Romanian medical students did not score that high on perceived stress and burnout, and this is in accordance with the findings that state that individuals who have a higher risk for developing symptoms acute stress, insomnia, anxiety or depression were the ones confirmed or suspected to be infected. In our study, medical students declared in a large proportion, up to $85.3 \%$ that they were not or had not been infected. Moreover, $71 \%$ of them declared that they did not know a close person to be ill, which is considered another risk factor. So, the Romanian medical students were not among infected individuals, nor among people with suspected infection, but they could have become part of the group that might provide care for patients suffering of COVID-19.(31,32)

We can only agree and stress the importance of the statement of Petzold et al (2020): "In the current situation, fears regarding the COVID-19 pandemic have to be seen as normal consequences in an exceptional situation rather than as pathologic reactions". (20)

We acknowledge the limitation of our method of collecting responses, via online, but this had to be done in accordance with the State of Emergency and the epidemiological conditions in Romania at the moment of the survey.

\section{CONCLUSIONS}

In general, Romanian medical students perceived a moderate level of stress and a burnout value that indicated that some attention was needed as they might have been candidates to burnout. Female medical students perceived a higher level of stress and showed a higher level of burnout, and also scored higher for anxiety and fear related to COVID-19.

Medical students with a personal history of mental illness scored higher on perceived stress, burnout, and anxiety and fear related to COVID-19. Students diagnosed with a psychiatric disorder during the pandemic showed signs that they were on the road to burnout, with changes needed to be done at the time.

There were statistically significant positive correlations, of various degrees between perceived stress, burnout, anxiety and fear related to COVID-19, with the strongest one observed for the perceived stress and burnout, in Romanian medical students.

\section{Acknowledgments:}

Krisztina-Agota Armean and Codruța-Alina Popescu are authors with equal contribution.

The authors express their gratitude to all the respondents for their time and energy put in filling in the online survey. We express our gratitude to Mr. Alexandru Răducu, who voluntarily developed and manages our website, www.psysafe.org, and to all our dear collaborators and friends who inspired us.

\section{REFERENCES}

1. Healy D. Rhythm and blues. Neurochemical, neuropharmacological and neuropsychological implications of a hypothesis of circadian rhythm dysfunction in the affective disorders. Psychopharmacology (Berl) [Internet]. 1987 Nov;93(3). Available from: http://link.springer.com/10.1007/BF00187243.

2. Murray G, Gottlieb J, Swartz HA. Maintaining Daily Routines to Stabilize Mood: Theory, Data, and Potential Intervention for Circadian Consequences of COVID-19. Can J Psychiatry; 2020.

3. Jones PJ, Ma R, McNally RJ. Bridge Centrality: A Network Approach to Understanding Comorbidity. Multivariate Behav Res [Internet]. 2019 Jun 10;1-15. Available from: https://www.tandfonline.com/doi/full/10.1080/00273171.201 9.1614898

4. Cramer AOJ, Waldorp LJ, van der Maas HLJ, Borsboom D. Comorbidity: A network perspective. Behav Brain Sci [Internet]. 2010 Jun 29;33(2-3):137-50. Available from: https://www.cambridge.org/core/product/identifier/S0140525 X09991567/type/journal_article.

5. President of Romania. Decret semnat de Presedintele României, domnul Klaus Iohannis, privind instituirea stării de urgență pe teritoriul României [Internet]. Available from: https://www.presidency.ro/ro/media/decrete-si-acteoficiale/decret-semnat-de-presedintele-romaniei-domnulklaus-iohannis-privind-instituirea-starii-de-urgenta-peteritoriul-romaniei.

6. Ministry of Internal Affairs. Ordinul 74.522/17.03.2020 [Internet]. March 17th. 2020. p. 2. Available from: https://www.mai.gov.ro/informare-covid-19-grupul-decomunicare-strategica-17-martie-ora-22-00/.

7. Carol Davila University of Medicine and Pharmacy Bucharest. Press Release - 200 Medical Students Volunteer to Help Physicians [Internet]. 2020. Available from: 


\section{PUBLIC HEALTH AND MANAGEMENT}

https://umfcd.ro/comunicat-de-presa-peste-200-de-studentiai-umfcd-pregatiti-sa-se-alature-medicilor/.

8. Stringaris A, Cohen P, Pine DS, Leibenluft E. Adult Outcomes of Youth Irritability: A 20-Year Prospective Community-Based Study. Am J Psychiatry [Internet]. 2009 Sep;166(9):1048-54. Available from: http://psychiatryonline.org/doi/abs/10.1176/appi.ajp.2009.08 121849.

9. Stringaris A, Taylor E. Disruptive Mood [Internet]. New York: Oxford University Press; 2015. 176 p. Available from: http://oxfordmedicine.com/view/10.1093/med/97801996745 41.001.0001/med-9780199674541.

10. Malhi GS, Byrow Y, Fritz K, Berk L, Berk M. Does irritability determine mood depending on age? Aust $\mathrm{N} \mathrm{Z} \mathrm{J}$ Psychiatry. 2017;51(3):215-6.

11. Vidal-Ribas P, Brotman MA, Valdivieso I, Leibenluft E, Stringaris A. The Status of Irritability in Psychiatry: A Conceptual and Quantitative Review. J Am Acad Child Adolesc Psychiatry [Internet]. 2016;55(7):556-70. Available from: http://dx.doi.org/10.1016/j.jaac.2016.04.014.

12. Eyre O, Langley K, Stringaris A, Leibenluft E, Collishaw S, Thapar A. Irritability in ADHD: Associations with depression liability. J Affect Disord [Internet] 2017;215(September 2016):281-7. Available from: http://dx.doi.org/10.1016/j.jad.2017.03.050.

13. Eyre O, Riglin L, Leibenluft E, Stringaris A, Collishaw S, Thapar A. Irritability in ADHD: association with later depression symptoms. Eur Child Adolesc Psychiatry [Internet]. 2019;28(10):1375-84. Available from: https://doi.org/10.1007/s00787-019-01303-x.

14. Cohen S, Kamarck T, Mermelstein R. A Global Measure of Perceived Stress. J Health Soc Behav. 1983;24:386-96.

15. Shields K. Burnout Rating Scale. In: The Tiger's Mouth: An Empowerment Guide For Social Action. Self-published; 2000. p. 130.

16. Ho SMY, Kwong-Lo RSY, Mak CWY, Wong JS. Fear of Severe Acute Respiratory Syndrome (SARS) Among Health Care Workers. J Consult Clin Psychol [Internet]. 2005 Apr;73(2):344-9. Available from: http://doi.apa.org/getdoi.cfm?doi=10.1037/0022006X.73.2.344.

17. Ahorsu DK, Lin C-Y, Imani V, Saffari M, Griffiths MD, Pakpour AH. The Fear of COVID-19 Scale: Development and Initial Validation. Int J Ment Health Addict [Internet] 2020 Mar 27; Available from: http://link.springer.com/10.1007/s11469-020-00270-8.

18. Wang Y, Hu Z, Feng Y, Wilson A, Chen R. Changes in network centrality of psychopathology symptoms between the COVID-19 outbreak and after peak. Mol Psychiatry [Internet]. 2020; Available from: http://dx.doi.org/10.1038/s41380-020-00881-6.

19. Rogers JP, Chesney E, Oliver D, Pollak TA, McGuire P, Fusar-Poli $\mathrm{P}$, et al. Psychiatric and neuropsychiatric presentations associated with severe coronavirus infections: a systematic review and meta-analysis with comparison to the COVID-19 pandemic. The Lancet Psychiatry [Internet] 2020 Jul;7(7):611-27. Available from: https://linkinghub.elsevier.com/retrieve/pii/S2215036620302 030.

20. Petzold MB, Bendau A, Plag J, Pyrkosch L, Mascarell Maricic L, Betzler F, et al. Risk, resilience, psychological distress, and anxiety at the beginning of the COVID-19 pandemic in Germany. Brain Behav. 2020;10(9):1-10.

21. Popescu CA, Bob MH, Junjan V, Armean SM, Buzoianu AD. Factors Influencing Alcohol and Illicit Drug Use Amongst First Year Medical Students. Acta Medica Transilv. 2014;2(31):174-8.
22. Năsui BA, Popa M, Popescu CA. Drinking Patterns and Behavioral Consequences: A Cross-Sectional Study Among Romanian University Students. Slov J Public Heal [Internet]. 2016 Mar 1;55(1):59-66. Available from: https://www.sciendo.com/article/10.1515/sjph-2016-0009.

23. Popescu CA, Sîrbu AC, Armean SM, Buzoianu AD. Depression, academic stress and substance use among medical students in Romania. In: AMEE - An International Association for Medical Education, 24-28 August 2019. Vienna; 2019.

24. Năsui BA, Popescu CA. A study regarding alcohol consumption and knowledge on alcohol among Romanian medical students. Palestrica Third Millenn - Civiliz Sport [Internet]. 2018 Dec 27;19(4):203-7. Available from: http://www.pm3.ro/palestrica-of-the-third-millenniumcivilization-and-sport-vol-20-no-4-october-december2018/a-study-regarding-alcohol-consumption-andknowledge-on-alcohol-among-romanian-medical-students/.

25. Armean SM, Popescu CA, Sîrbu AC, Buzoianu AD. The importance of academic stress in the onset of depression and substance use in medical students. In: The 19th WPA World Congress of Psychiatry, 21-24 August 2019. Lisbon; 2019.

26. Sîrbu AC, Armean SM. Evaluarea riscului de abuz de substanțe psihoactive în relație cu stresul academic. Iuliu Hatieganu University of Medicine and Pharmacy; 2020.

27. Vindegaard N, Benros ME. COVID-19 pandemic and mental health consequences: Systematic review of the current evidence. Brain Behav Immun [Internet]. 2020 Oct;89(January):531-42. Available from: https://linkinghub.elsevier.com/retrieve/pii/S0889159120309 545.

28. Pappa S, Ntella V, Giannakas T, Giannakoulis VG, Papoutsi E, Katsaounou P. Prevalence of depression, anxiety, and insomnia among healthcare workers during the COVID-19 pandemic: A systematic review and meta-analysis. Brain Behav Immun [Internet]. 2020 Aug;88(January):901-7. Available from: https://linkinghub.elsevier.com/retrieve/pii/S0889159120308 $45 \mathrm{X}$.

29. Huang Y, Zhao N. Generalized anxiety disorder, depressive symptoms and sleep quality during COVID-19 outbreak in China: a web-based cross-sectional survey. Psychiatry Res [Internet]. 2020 Jun;288:112954. Available from: https://linkinghub.elsevier.com/retrieve/pii/S0165178120306 077.

30. Özdin S, Bayrak Özdin Ş. Levels and predictors of anxiety, depression and health anxiety during COVID-19 pandemic in Turkish society: The importance of gender. Int J Soc Psychiatry [Internet]. 2020 Aug 8;66(5):504-11. Available from: http://journals.sagepub.com/doi /10.1177/0020764020927051.

31. L, Lu Z-A, Que J-Y, Huang X-L, Liu L, Ran M-S, et al. Prevalence of and Risk Factors Associated With Mental Health Symptoms Among the General Population in China During the Coronavirus Disease 2019 Pandemic. JAMA Netw Open [Internet]. 2020 Jul 1;3(7):e2014053. Available from:

https://jamanetwork.com/journals/jamanetworkopen/fullarticl e/2767771

32. Wang C, Pan R, Wan X, Tan Y, Xu L, McIntyre RS, et al. A longitudinal study on the mental health of general population during the COVID-19 epidemic in China. Brain Behav Immun [Internet]. 2020 Jul;87(January):40-8. Available from:

https://linkinghub.elsevier.com/retrieve/pii/S0889159120305 110. 